\begin{abstract}
NASA Technical Memorandum 104194 AVSCOM Technical Report 91-B-020
\end{abstract}

\title{
Optimizing Tuning Masses for Helicopter Rotor Blade Vibration Reduction Including Computed Airloads and Comparison with Test Data
}

Jocelyn I. Pritchard Howard M. Adelman Joanne L. Walsh Matthew L. Wilbur

January 1992

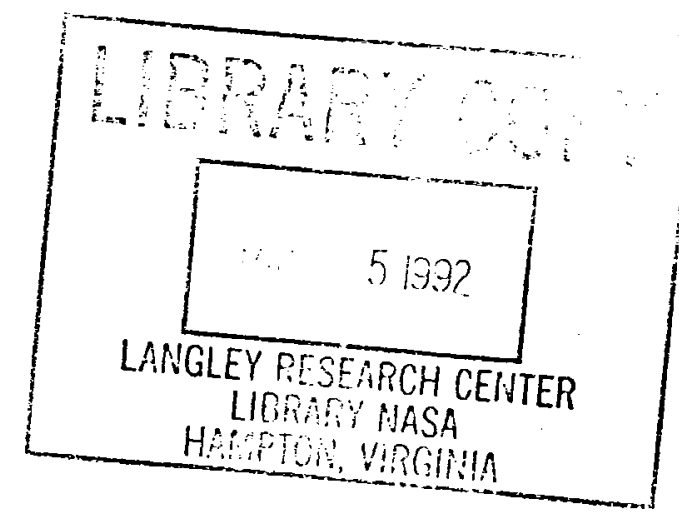

National Aeronautics and Spaco Administration

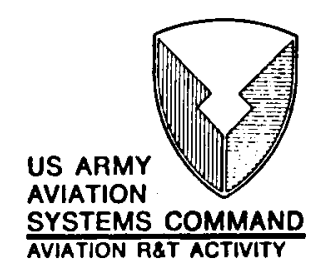


?

$\therefore$ 


\title{
Optimizing Tuning Masses For Helicopter Rotor Blade \\ Vibration Reduction Including Computed Airloads \\ And Comparison With Test Data
}

\author{
Jocelyn I. Pritchard* \\ Howard M. Adelman** \\ Joanne L. Walsh + \\ Matthew L. Wilbur++ \\ NASA Langley Research Center \\ Hampton, Virginia
}

\begin{abstract}
This paper describes the development and validation of mass of fixed value on a blade model to reduce the hub an optimization procedure to systematically place tuning masses along a rotor blade spanto minimize vibratory loads. The masses and their corresponding locations are the design variables that are manipulated to reduce harmonics of hub shear for a four-bladed rotor system without adding a large mass penalty. The procedure incorporates a comprehensive helicopter analysis to calculate the airloads. Predicting changes in airloads due to changes in design variables is an important feature of this research. The procedure was applied to a one-sixth, Mach-scaled rotor blade model to place three masses and then again to place shear for three flight conditions. The analytical results were compared to experimental data from a wind tunnel test performed in the Langley Transonic Dynamics Tunnel. The correlation of the mass location was good and the trend of the mass location with respect to flight speed was predicted fairly well. However, it was noted that the analysis was not entirely successfulat predicting the absolute magnitudes of the fixed-system loads.

\section{Nomenclature}

six masses. In both cases the added mass was able to achieve significant reductions in the hub shear. In addition, the procedure was applied to place a single

- Research Engineer, Aerostructures Directorate, Member AHS

"Doputy Head, Interdisciplinary Research Office, Associate Fellow AIAA, Member AHS

$S_{k} \quad$ amplitude of $k$ th harmonic of shear

'Research Engineer, Member AIAA, AHS

$X_{j} \quad$ location of $j$ th tuning mass

"Rosearch Engineer, Aerostructures Dircectorate, Member AHS

$\beta_{k} \quad$ scalar design variables appearing in the ob-
\end{abstract}


jective function and constraints

$\mu \quad$ advance ratio (ratio of fonward flight speed to tip speed)

$\omega_{\mathrm{i}} \quad$ ith natural frequency

$\bar{\omega}_{\mathrm{i}} \quad \omega_{\mathrm{i}} / \Omega$

$\bar{\omega}_{\mathrm{li}} \quad$ lower bound on $\bar{\omega}_{\mathrm{i}}$

$\bar{\omega}_{\text {ui }} \quad$ upper bound on $\bar{\omega}_{\mathrm{i}}$

$\Omega \quad$ rotational speed of rotor blade

\section{Introduction}

Since helicopter vibration is transmitted from the rotor blade to the fuselage through a time dependent shear force at the hub, methods for reducing vibration through reduction of hub shear have long been a subject of study. An example of this is vibration reduction of rotor blades through passive control. For instance, pendulum absorbers ${ }^{1}$, active isolation devices 2 , additional damping ${ }^{2-3}$, and vibration absorbers which create anti-resonances ${ }^{4-5}$ have all shown promise in reducing blade vibratory response. Historically, frequency placement has been the principal technique for passively reducing blade vibration ${ }^{6}$. Another form of passive control is to alter the mass and stiffness distributions of the blade. These modifications tailor the mode shapes to achieve orthogonality to the airloading thereby reducing the generalized force and response of the blade ${ }^{7}$. This is generally done in a late stage of the design process.

The current trend in engineering design of aircraft is to incorporate critical requirements from all pertinent disciplines into an early phase of the design process to avoid costly modifications after a problem has been detected ${ }^{8}$. In the preliminary stage of design, a large number of design variables are free to be chosen in order to satisfy important multidisciplinary considerations. It is in this stage that passive control of vibration can play an important role. The design process is a labor-intensive effort, however, mathematical optimization techniques allow for efficient and thorough searches of the design possibilities while satisfying a large number of conflicting design requirements from many different disciplines. For example, reference 9 used optimization methods to study the interaction of structural properties with airload distributions in designing blades for low vibration. The structural properties included mass and stiffness distributions. The airload distributions included higher harmonic lift components and aerodynamic pitching moments which are the primary sources of vibration in helicopter rotor blades. Comparison of the vibration characteristics from three analytical design strategies showed the benefits of using an automated structural optimization procedure with a coupled aeroelastic analysis. Another example where optimization was successfully applied to the design of low vibration rotor blades was reported in reference 10 and 11 where several alternative optimization formulations were investigated and their benefits revealed. References 10 and 11 did not use computed airloads in the analyses. Reference 12 discusses an optimization procedure for designing a low vibration rotor blade. Wind tunnel tests of the blade showed that the design proved to be better than a rotor designed using the traditional approach of frequency placement. A comparison between the analytical results and test data revealed that the trends and reductions in load levels were predicted well but the absolute values of the loads at given airspeeds were predicted less accurately.

Reference 13 described a procedure for placing and sizing tuning masses at strategic locations along the blade span to tailor the mode shapes. This procedure used formal mathematical programming techniques in conjunction with a finite element program to model a simplified blade and calculate the dynamic response. The airloads used in the analysis repre- 
sented a set of harmonics typical of a four-bladed rotor system ${ }^{7}$. The loads did not vary with changes in the masses or their locations. The purpose of this paper is to describe the enhancement and validation of the method described in reference 13. The enhancements include the incorporation of a comprehensive helicopter analysis CAMRAD/JA ${ }^{14}$ into the optimization procedure which yields a more realistic blade model and calculated airloads. The validation is accomplished by comparing the analytical results with experimental data from wind tunnel tests.

Problem Definition and Formulation

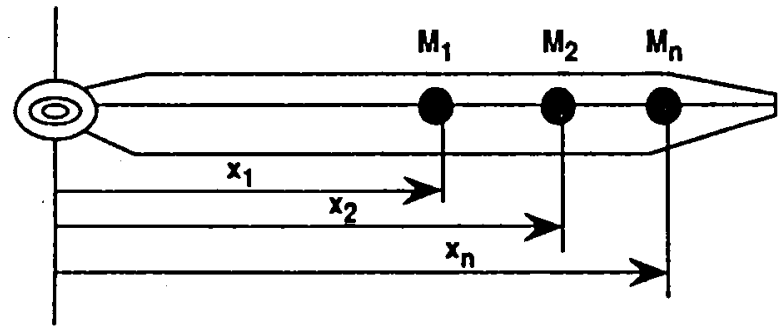

Figure 1. Design variable definition for optimizing magnitudes and locations of tuning masses

The design goal is to find the optimum combination of masses and their locations (Fig. 1) to reduce the vertical hub shear. The method entails formulating and solving an optimization problem in which the tuning masses, M's and corresponding locations, X's are design variables that are manipulated to minimize the objective function. Equation (1) defines the objective funclion, $f$ which is a combination of vertical hub shear and added mass.

$$
f=\left(1+\sum_{k=1}^{K} \beta_{k}\right) \sum_{j=1}^{J} M_{j}
$$

The objective function includes additional design vari- ables, $\beta_{k}$ which also appear in the constraints as "upper limits" on the shear harmonic amplitudes, $S_{k}$.

$$
S_{k} / \beta_{k}-1 \leq 0 \quad k=1,2, \ldots, K
$$

$K$ represents the number of shear harmonics to be included in the objective function. By convention a constraint is satisfied if its value is less than or equal to zero. Consequently, the optimizer will tend to decrease the values of $\beta_{k}$ to minimize the objective function but will also tend to increase the values of $\beta_{k}$ to satisfy the constraints. This results in a compromise on the values of $\beta_{k}$ which forces a reduction in the values of Sk thus reducing the hub shear harmonics while incurring the smallest possible mass penalty. Additional constraints include upper and lower bounds on the natural frequencies of the blade to avoid resonance as shown in equation (3).

$$
\left.\begin{array}{l}
\bar{\omega}_{\mathrm{i}} / \bar{\omega}_{\mathrm{ui}}-1 \leq 0 \\
1-\bar{\omega}_{\mathrm{i}} / \bar{\omega}_{\mathrm{li}} \leq 0
\end{array}\right\} \mathrm{i}=1,2, \ldots, \mathrm{I}
$$

where $\bar{\omega}_{i}=\omega_{i} / \Omega, \omega_{i}$ is the ith natural frequency, $\bar{\omega}_{\mathrm{ui}}$ and $\bar{\omega}_{\mathrm{li}}$ are the upper and lower bounds on $\omega_{\mathrm{i}}$ respectively and $\mathrm{l}$ is the number of constrained frequencies.

\section{Analyses}

The analyses that are used in the procedure are the comprehensive helicopter analysis code, CAMRAD/ $\mathrm{JA}^{14}$, the optimization code, CONMIN ${ }^{15}$ and an approximate analysis to reduce the number of CAMRAD/ JA analyses during the iterative process. CAMRAD/JA calculates rotor performance, loads, vibration mode shapes and frequencies, aeroelastic stability and re- 
sponse. In this study, CAMRAD/JA was used to calculate frequencies, airloads and hub loads. The structural model of the rotor is based on engineering beam theory for rotating wings with large pitch and pretwist. The frequencies and mode shapes are computed using a modified Galerkin analysis. The rotor aerodynamic model is based on lifting-line theory and uses steady two-dimensional airfoilcharacteristics provided intables of section lift, drag, and pitching moment versus Mach number and angle of attack. The analysis includes unsteady aerodynamic forces from thin airfoil theory and the induced velocity is obtained from either a uniform inflow model or a vortex wake model. A detailed description of the theory is given in reference 14 .

CONMIN is a general purpose optimization program that uses the method of feasible directions for constrained function minimization and the conjugate direction method of Fletcher and Reeves for unconstrained minimization problems. The approximate analysis uses a linear Taylor Series expansion to approximate the objective function and constraints for the iterative portion of the optimization procedure to save computational effort.

\section{Qrganization of the Procedure}

A flowchart of the optimization procedure is illustrated in figure 2. The overall procedure consists of two nested loops. Each pass through the outer loop is referred to as a cycle which involves a full analysis and a sensitivity calculation. The sensitivity analysis includes calculating finite-difference derivatives of the objective function and the constraints with respect to the design variables. The first step is to generate the model of the blade, excluding tuning masses. The design variables (masses and locations) then determine where and how much mass should be placed on the blade. Next the modal analysis is performed and the

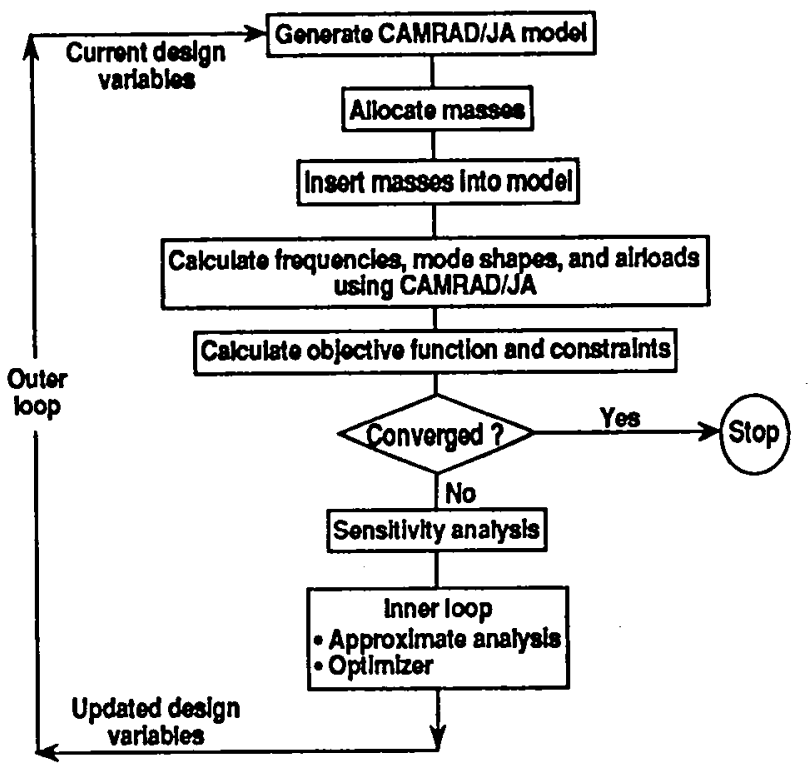

Figure 2. Flow chart for optimization procedure

airloads and hub shears are computed using CAMRAD/ $J A$, and the objective function and constraints are calculated. The inner loop consists of the optimization program CONMIN and the approximate analysis for calculating values of the objective function and constraints. Once the inner loop has converged, the next cycle begins, using updated values of the design variables. The process continues until convergence of the outer loop is achieved. The major improvement in the procedure over that of reference 13 occurs in the outer loop where the airloads are calculated by CAMRAD/JA. The use of CAMRAD/JA enables the change in airloads due to changes in the design variables to be taken into account.

\section{Demonstration of the Method}

The model used to demonstrate the procedure is a 4-bladed, one-sixth, Mach-scaled representation of a design intended to satisfy the requirements for the "growth" version of the U.S. Army's UH-60A (Black Hawk) helicopter. Each blade (shown in figure 3) weighs about $3 \mathrm{lbs}$ and has three sets of advanced 


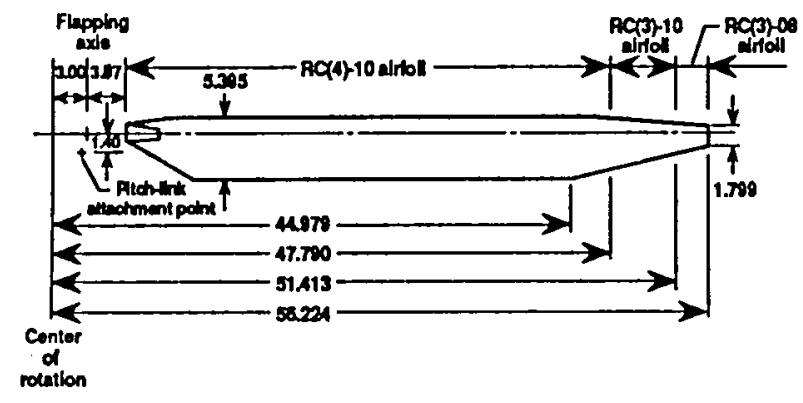

Figure 3. Rotor blade geometry (Dimensions are in inches)

airfoils, $R C(4)-10^{16}, R C(3)-10^{17}$, and $R C(3)-08^{17}$. The planform is tapered with a -16 degree linear twist. The calculations were performed in CAMRAD/JA using five flap/lag bending modes and two torsion modes. Each blade was modeled with 18 aerodynamic segments and 50 structural segments. The chordwise center of gravity, aerodynamic center, and elastic axis were coincident and located at the quarter-chord. The rotor was trimmed to prescribed values of thrust and zero flapping angles using nonuniform inflow with a prescribed wake geometry. The 4P blade vertical shear" is generally the primary source of vertical loads in a four-bladed rotor configuration and the $3 \mathrm{P}$ and $5 \mathrm{P}$ blade vertical shears contribute to the hub moments. Therefore, these three quantities were the major focus for reduction in this optimization study. The flight condition was forward flight at an advance ratio of $\mu=0.35$ and a thrust condition of $\mathrm{C}_{\mathrm{T}}=\mathbf{0 . 0 0 8 1}$ which signifies a full scale gross weight of $18,500 \mathrm{lbs}$.

Table 1 shows the results obtained from applying the optimization procedure to place three tuning masses along the span of the blade model. Starting with the baseline blade (no added mass), the procedure was able to reduce the $3 \mathrm{rd}, 4$ th, and 5 th harmonics of shear by $8 \%, 8 \%$, and $4 \%$ respectively by adding $0.338 \mathrm{lbm}$ of

\footnotetext{
* It is customary in rotorcraft dynamics to use the notution $\mathrm{N} / \mathrm{rev}$ or $\mathrm{NP}^{\text {' }} \mathrm{w}$ denote frequencies or harmonics of loading at $\mathbf{N}$ times the rotational specd of the blade.
}

Table 1. Comparison of baseline and optimized designs from 3-mass and 6-mass optimization procedures

\begin{tabular}{|c|c|c|c|}
\hline & $34-444$ & $440 \%$ & 6448 \\
\hline $14145, b_{1}$ & 0.00 & 0.028 & 0.059 \\
\hline 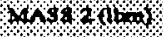 & 0.00 & 0.155 & 0.022 \\
\hline 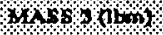 & 0.00 & 0.155 & 0.302 \\
\hline 4484444, & 0.00 & 0.00 & 0.304 \\
\hline 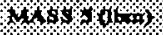 & 0.00 & 0.00 & 0.280 \\
\hline $14 A-801,1$ & 0.00 & 0.00 & 0.256 \\
\hline 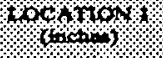 & - & 26.42 & 26.80 \\
\hline 1 & - & 23.61 & 26.32 \\
\hline 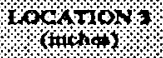 & - & 29.23 & 25.42 \\
\hline roo 110,4 & - & - & 27.14 \\
\hline 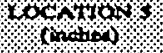 & - & - & 26.29 \\
\hline 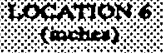 & 一 & - & 26.90 \\
\hline $844 t$ & 18.30 & 16.80 & 13.90 \\
\hline 1804 & 11.50 & 10.60 & 7.57 \\
\hline 1001 & 4.80 & 4.60 & 3.25 \\
\hline
\end{tabular}

tuning mass which is about $11.5 \%$ of the nominal blade weight. The mass was added between 42 and 52 percent of the blade span. The baseline blade was originally designed for low vibration so these reductions in shear from the baseline design although seemingly modest, are considered to be significant.

As a matter of interest the procedure was also applied to place six masses and results are also shown in table 1. In this case, the optimizer placed all masses between 45 and 48 percent of the blade span. The procedure reduced the $3 \mathrm{rd}, 4 \mathrm{th}$, and 5 th harmonics of shear from the baseline values by $24 \%, 34 \%$, and $32 \%$ respectively with a total addition of $1.2 \mathrm{lbm}$ of tuning mass. This is a sizable reduction in shear, (approximately four times the reduction in the 3-mass case) 
however, the added mass represents about 30 percent of the mass of the baseline blade. Consequently, this solution to the vibration problem would probably not be adopted in a practical design situation. Nonetheless, this result verifies our intuition that use of additional mass design variables improves vibration reduction but with a significant increase in the weight penalty.

\section{Comparison with Test Data}

Reference 18 describes results of wind tunnel tests performed in the NASA Langley Transonic Dynamics Tunnel (TDT) on the blade test article shown in figure 4. The test article, based on the model described in the

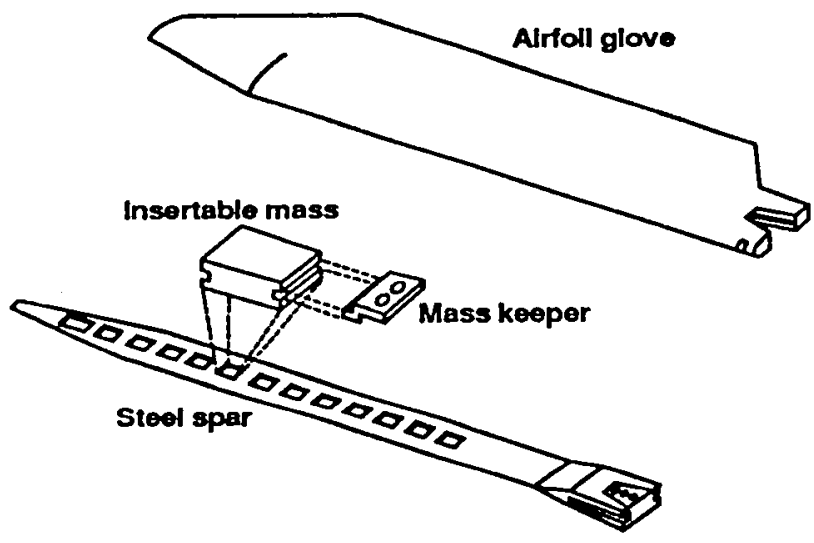

Figure 4. Model rotor blade components

previous section, was designed to study passive means forminimizing fixed-system loads and has the capability of adding nonstructural masses at various intervals of the blade span. This test provided an opportunity to validate the present optimization procedure. Adescription of the model, test set-up, and the reduced data are given in reference 18 . The test involved placing a single mass of fixed value $(.27 \mathrm{lbm})$ at various locations along the blade span to determine the effectiveness in reducing 4P hub shears and moments for several different flight conditions.

Reference 18 shows several data plots of $4 \mathrm{P}$ normal force as a function of mass location on the blade. Many of the curves are very flat and suggest that the mass location does not significantly affect the hub shear for all flight conditions. Since optimization works best for problems with well defined minimums, only selected cases were included in this study.

The optimization procedure was applied to this model for the placement of a single mass at advance

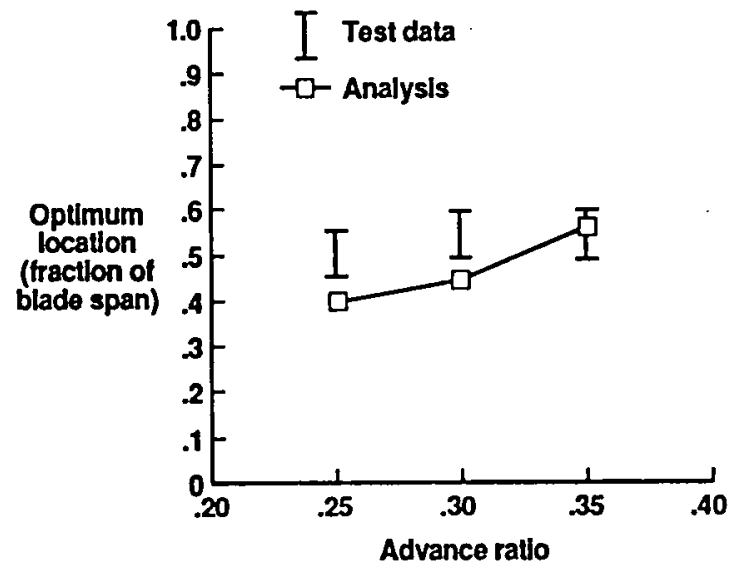

Figure 5. Comparison of optimum location of single mass with test data

ratios of $0.25,0.30$, and 0.35 and a thrust condition of $\mathrm{C}_{T}=\mathbf{0 . 0 0 8 1}$. Comparisons between the optimization results and the test data are summarized in Figure 5. The measured values of the optimum locations are shown as 10 percent ranges of the blade span since the data was only available at 10 percent increments of the blade span. For the 0.35 advance ratio case, the optimization procedure predicted an optimum location within the range of the test data. The other two cases $(0.25,0.30)$ were $11 \%$ and $12 \%$ respectively below the lower bound of the range. This is fairly good agreement considering the well-known difficulty of predicting fixedsystem loads.

In order to verify the mechanism by which the hub loads are decreased figures 6 and 7 illustrate examples 
of the changes in the calculated mode shapes and airloads respectively from the baseline to the optimized design. The simultaneous changes in the mode shapes and airloads result in a reduction of the generalized force and subsequently the hub shear. The sizeable

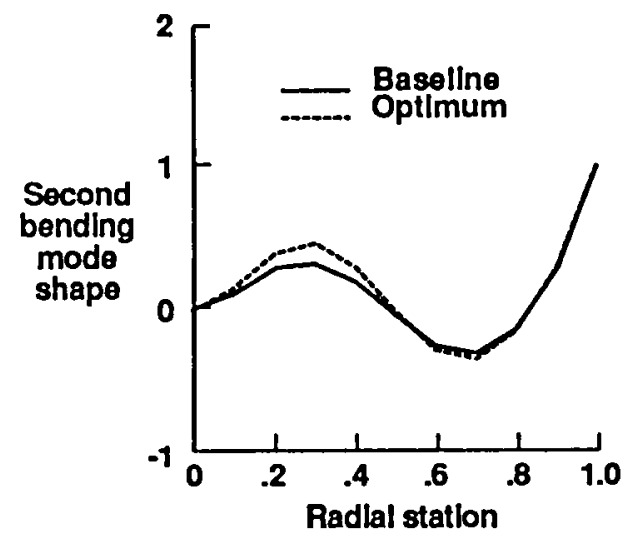

Figure 6. Comparison of mode shapes from baseline and optimum designs

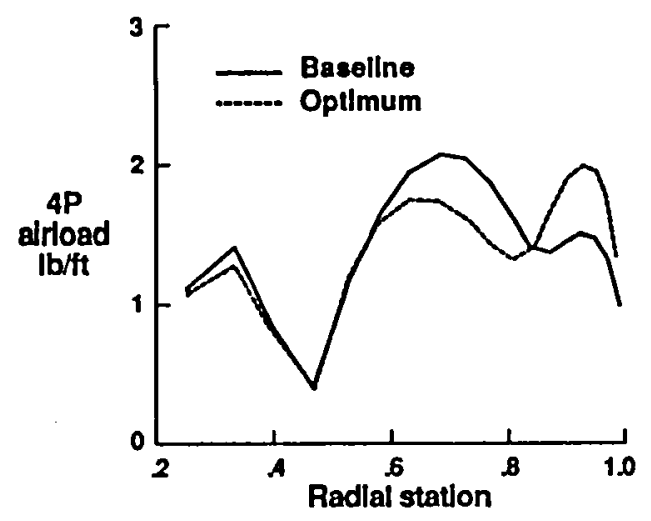

Figure 7. Comparison of 4P airloads from baseline and optimum designs

change in the airload distribution resulting from the changes in the design variables suggests that neglecting this effect would be erroneous.

\section{Additional Details of Design Comparisons}

Table 2 shows some additional details of the three results for the single mass placement optimization. The
Table 2. Predicted versus measured results for single mass placement to reduce hub shear

\begin{tabular}{|c|c|c|c|c|c|c|}
\hline & \multicolumn{2}{|c|}{ Advence nio $=0.25$} & \multicolumn{2}{|c|}{ Advence ntio $=0.30$} & \multicolumn{2}{|c|}{ Advence ratio $=0.35$} \\
\hline & Predicted & Merruedt & Prottered & Monturf & Prodeted & Mentred: \\
\hline $\begin{array}{l}\text { Opimum } \\
\text { loction of } \\
\text { mess, } 1 R\end{array}$ & 0.40 & 0.48 & 0.44 & 0.52 & 0.56 & 0.52 \\
\hline $\begin{array}{l}\text { SA nio } \\
\text { finalfrical }\end{array}$ & 0.94 & 0.93 & 0.92 & 0.90 & 0.90 & 0.92 \\
\hline $\begin{array}{l}\$ 4 \text { (ibn } \\
\text { Leical design } \\
\text { mass }=0 \text { lbm }\end{array}$ & 1020 & 20.10 & 7.10 & 3750 & 11.15 & 49.00 \\
\hline $\begin{array}{l}S 4 \mathrm{nbl}) \\
\mathrm{Fmal} \\
\mathrm{man}=0,27 \\
\mathrm{lbm}\end{array}$ & 9.60 & 18.80 & 6.57 & 33.60 & 10.02 & 45.00 \\
\hline
\end{tabular}

- Based on faired curve through erperimentel data points

optimum location was in fair agreement with the test data and the relative change in hub shear from the baseline to tinal design was also comparable between the optimization and test measurements for all three cases. However, the absolute values of the hub shear were grossly underpredicted. Unfortunately, this represents the current state of the art in prediction of fixed system loads in rotorcraft systems (see for example Refs 19,20). Although it is outside the scope of this paper to either investigate the reasons for or to recommend corrective action for this shortcoming, the authors feel obliged to point out its existence. Further we are aware of a number of efforts in progress to improve the fidelity of fixed system loads prediction. For example, some of the more fruitful approaches involve the investigations of accurate calculation of rotor airloads (Refs $21,19,22)$.

\section{Concluding Remarks}

This paper described the development and validation of an optimization procedure to systematically place tuning masses along a rotor blade span to mini- 
mize vibratory response. The masses and their corresponding locations were the design variables that were manipulated to reduce harmonics of hub shear for a four-bladed rotor system without adding a large mass penalty. The procedure incorporated a comprehensive helicopter analysis to calculate the airloads. This procedure enabled the changes in airloads due to the changes in design variables to be taken into account.

The procedure was first applied to a one-sixth, Mach-scaled rotor blade model for two cases: (1) the placement of three masses and (2) the placement of six masses. The optimized three-mass configuration reduced the $3 \mathrm{rd}, 4 \mathrm{th}$, and 5 th harmonics of shearbetween 4 and 8 percent. The optimized six-mass configuration reduced these shear harmonics between 24 and 34 percent, although four times the mass was added over a smaller region of the blade.

The optimizer was then compared to test data for placing a single mass of fixed value on a blade model to reduce the $4 \mathrm{P}$ hub shear for three flight conditions. $A$ wind tunnel test was performed in the Langley Transonic Dynamics Tunnel (TDT) on a blade test article. The analytical results were compared to the experimental data and the trend of the mass location with respect to llight speed was predicted fairly well. At the same time it was noted that the analysis used was not entirely successful at predicting the absolute magnitudes of fixed-system loads.

\section{References}

1. Hamouda, N. H., and Pierce, G. A., "Helicopter Vibration Suppression Using Simple Pendulum Absorbers on the Rotor Blade," Presented at the American Helicopter Society Northeast Region National Specialists' Meeting on Helicopter Vibration, Hartford, Connecticut, November 1981.
2. Reichert, G., "Helicopter Vibration Control - A Survey," Vertica 5, 1-20, 1981.

3. Rogers, L., "Damping as a Design Parameter," Mechanical Engineering, 108, No.1, January 1986.

4. Wang, B. P., Kitis, L., Pilkey, W. D., and Palazzolo, A., "Synthesis of Dynamic Vibration Absorbers," Journal of Vibration, Acoustics, Stress, and Reliability in Design, 107/161, April 1985.

5. Kitis, L., Pilkey,W. D., and Wang, B. P., "Optimal Frequency Response Shaping by Appendant Structures," Journal of Sound and Vibration, 95 (2), 161-175, 1984.

6. Peters, D. A., Ko, T., Korn, A., and Rossow, M. P., "Design of Helicopter Rotor Blades for Desired Placement of Natural Frequencies," 39th Annual Forum of the American Helicopter Society, May 1983.

7. Taylor, R. B., "Helicopter Vibration Reduction By Rotor Blade Modal Shaping," Presented at the 38th Annual Fonum of the American Helicopter Society, Anaheim, California, May 1982.

8. Sobieszczanski-Sobieski, J., "Sensitivity Analysis and Multidisciplinary Optimization for Aircraft Design: Recent Advances and Results," Journal of Aircraft, Vol. 27, No. 12, December 1990, pp. 993-1001.

9. Yen, J. G., "Coupled Aeroelastic Hub Loads Reduction," AHS/NAl International Seminar, Nanjing, China, November 1985.

10. Davis, M. W. and Weller, W. H., "Application Of Design Optimization Techniques to Rotor Dynamics Problems," AHS Journal, Vol. 33, No. 3, July 1988.

11. Weller, W. H., and Davis, M. W., "Wind Tunnel Tests of Helicopter Blade Designs Optimized for Minimum Vibration," AHS Journal, Vol. 34, No. 3, July 1989.

12. Young, D. K., and Tarzanin, F. J., "Structural Optimization and Mach Scale Test Validation of a Low Vibration Rotor," Proceedings ofthe 47th Annual Forum of the American Helicopter Society, Phoenix, Arizona, May 1991, pp. 955-968. 
13. Pritchard, J. I., and Adelman, H. M., "Optimal Placement of Tuning Masses For Vibration Reduction In Helicopter Rotor Blades," NASA TM 100562, AVSCOM TM 88-B-003, March 1988.

14. Johnson, W. A., "CAMRAD/JA - A Comprehensive Analytical Model of Rotorcraft Aerodynamics and Dynamics - Johnson Aeronautics Version," Volume I and II: Theory Manual and User's Manual, Johnson Aeronautics, Palo Alto, Califomia, 1988.

15. Vanderplaats, G. N., "CONMIN - A Fortran Program forConstrained Function Minimization - User's Manual," NASA TM X-62282, 1973.

16. Noonan, K. W., "Aerodynamic Characteristics of Two Rotorcraft Airfoils Designed for Application to the Inboard Region of a Main Rotor Blade," NASA TP-3009, AVSCOM TR-90-B-005, July 1990.

17. Bingham, G. J., and Noonan, K. W., "Two-Dimensional Aerodynamic Characteristics of Three Rotorcraft Airfoils at Mach Numbers From 0.35 to 0.90 ," NASA TP-2000, Avradcom TR-82-B-2, May 1982.

18. Wilbur, M. L., "Experimental Investigation of Helicopter Vibration Reduction Using Rotor Blade Aeroelastic Tailoring," Presented at the 47th Annual Fonum of the American Helicopter Society, Phoenix, Arizona, May 1991, pp. 969-977.

19. Yen, J. G., Yuce, M., Chao, C-F., and Schillings, J., "Validation of Rotor Vibratory Airloads and Application to Helicopter Response," Journal of the American Helicopter Society, Vol. 35, No. 4, October 1990.

20. Heffeman, R., Precetti, D. and Johnson, W., "Analysis and Correlation of SA349/2 Helicopter Vibration," AIAA-91-1222-CP, April 1991.

21. Bousman W. G., Young, C., Gilbert, N., Toulmay, F., Johnson, W., and Riley, M. J., "Correlation of Puma Airloads-Lifting-Line and Wake Calculation," NASA TM-102212, USAAVSCOM TR 89-A-006, November 1989.

22. Yamauchi, G. K., Heffernan, R. M., and Gaubert
M.,"Correlation of SA349/2 Helicopter Flight Test Data with a Comprehensive Rotorcraft Model," NASA TM88351, February 1987. 
Public reporting burden for this collection of Information is estimated to average I houf per response, including the time for reviewing Instructlons, searching existing data sources. gathering and mointaining the date needed, and completing and reviewing the collection of information. Send comments regarding this burden estimate or any other aspect of this

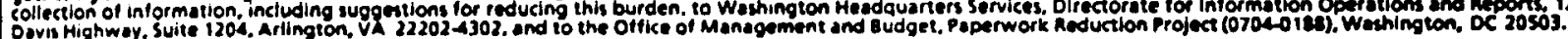

\begin{tabular}{l|l|l|l|l|} 
7. AGENCY USE ONLY (Leave blank) & 2. REPORT DATE & 3. REPORT TYPE AND DATES COVERED
\end{tabular}

4. TITLE AND SUBTITLE
Optimizing Tuning Masses for Hellcopter Rotor Blade January 1992

Technical Memorandum

Vibration Reduction Including Computed Airloads and Comparison with Test Data

6. AUTHOR(S)

Jocelyn I. Pritchard*, Howard M. Adelman, Joanne I. Walsh, Matthew I. Wilbur*

7. PERFORMING ORGANIZATION NAME(S) AND ADDRESS(ES)

NASA Langley Research Center, Hampton, VA 23665-5225

8. PERFORMING ORGANIZATION REPORT NUMBER

Aerostructures Directorate, U.S. Army-AVSCOM

Langley Research Center, Hampton, VA 23665-5225

9. SPONSORING/MONITORING AGENCY NAME(S) AND ADDRESS(ES)

National Aeronautics and Space Adminlstration

10. SPONSORING/MONITORING AGENCY REPORT NUMBER

Washington, DC 20546-0001

U.S. Army Aviation Systems Command

NASA TM-104194

St. Louis, MO 63120-1798

AVSCOM TR-91-B-020

11. SUPPLEMENTARY NOTES

$\star U . S$. Army-AVSCOM

Paper presented at the 33rd Structures, Structural Dynamics, and Materials

Conference, April 13-15, 1992, in Dallas, Texas.

12a. DISTRIBUTION/AVAILABILITY STATEMENT

Unclassified - Unlimited

Subject Category 05

\section{A8STRACT (Maximum 200 words)}

This paper describes the development and validation of an optimization procedure to systematically place tuning masses along a rotor blade span to minimize vibratory loads. The masses and their corresponding locations are the design variables that are manipulated to reduce harmonics of hub shear for a four-bladed rotor system without adding a large mass penalty. The procedure incorporates a helicopter analysis to calculate the airloads. Predicting changes in airloads due to changes in design variables is an important feature of this research.

The procedure was applied to a one-sixth, Mach-scaled rotor blade model to place three masses and then again to place six masses. In both cases the added mass was able to achleve significant reductions in the hub shear.

In addition, the procedure was applied to place a single mass of fixed value on a blade model to reduce the $4 \mathrm{P}$ hub shear for three flight conditions. The analytical results were compared to experimental data from wind tunnel tests performed in the Langley Transonic Dynamics Tunnel (TDT). The correlation of the mass location was good and the trend of the mass location with respect to flight speed was predicted fairly well.

14. SUBJECT TERMS
Optimization; Vibration Reduction; Mass Placement; Validation;
Rotorcraft Dynamics

Rotorcraft Dynamics

15. NUMBER OF PAGES

10

16. PRICE CODE

$\mathrm{AO} 2$

\begin{tabular}{|l|l|l}
\hline $\begin{array}{l}\text { 17. SECURITY CLASSIFICATION } \\
\text { OF REPORT }\end{array}$ & $\begin{array}{c}\text { 18. } \begin{array}{l}\text { SECURITY CLASSIFICATION } \\
\text { OF THIS PAGE } \\
\text { Unclassified }\end{array} \\
\text { Unclassified }\end{array}$ & $\begin{array}{c}\text { 19. SECURITY CLASSIFICATION } \\
\text { OF ABSTRACT } \\
\text { Unclassified }\end{array}$ \\
\hline
\end{tabular}

NSN 7540-01-2B0-5500

20. LIMITATION OF ABSTRACT 
NASA Technical Library

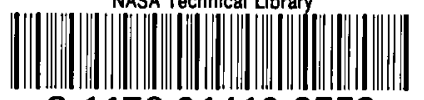

31176014102553 